\title{
REMOTE SENSING IMAGE TIME SERIES METRICS FOR DISTINCTION BETWEEN PASTURE AND CROPLANDS USING THE RANDOM FOREST CLASSIFIER
}

\author{
M. A. A. Rodrigues ${ }^{*}{ }^{1}$, H. N. Bendini ${ }^{1}$, A. R. Soares ${ }^{1}$, T. S. Körting ${ }^{1}$, L. M. G. Fonseca ${ }^{1}$ \\ ${ }^{1}$ Image Processing Division, National Institute for Space Research, INPE - \{marcos.almeida, hugo.bendini, anderson.soares, \\ thales.korting, leila.fonseca\}@inpe.br
}

KEY WORDS: Time series, Metric images, GEOBIA, Data cube, Random Forest

\begin{abstract}
:
Pasture and croplands play an important role in Brazil's economic and political scenarios, once its PIB (Raw Internal Product) is mainly based on what is exported from the rural production, such as meat and soybean, and government, with its regulations, is partresponsible for the establishment and maintaining of the conditions so that the trades can go well. In addition, these two types of land use correspond together to aprox. one third of the country extension. Moreover, frequently lands occupation is subject of discussion concerning its potential use for the reason of conflicts including Brazilian traditional communities, landless people and big farmers. Considering it, mapping pasture and croplands accurately is crucial for the country administration, in both economic and political spheres. Certainly, remote sensing is the very manner to tackle this issue, although this may not be an easy task due to the spectral similarity between these patterns. This work, hence, aims to distinct pasture from croplands in an experimental subset area of Brazilian Cerrado biome, using remote sensing metric images derived from one-year time series of the Landsat 8 products. In order to achieve this goal, we utilized six bands of the OLI sensor and calculated seven metrics, attaining a compiled dataset with 42 layers. We performed an object-based supervised classification with the Random Forest algorithm, considering both spectral and geometrical attributes. Results showed global accuracy of $80 \%$, with Kappa index of 0.6, and the potential time series have in separating targets spectrally similar.
\end{abstract}

\section{INTRODUCTION}

Pasture and croplands comprise two different types of land use, which are very important for Brazil, once its export matrix is mainly based on their production. Having these areas well mapped and accounted is then a strategic governmental action of knowing its territory, which allows making predictions of in and outcomes, acting like an ancillary for decision makers in protecting the country economy. Although their importance, and regarding this mapping is altogether conducted through remote sensing techniques, it is not an easy task to have these areas well mapped and distinguished due to their similarity in spectral response, causing confusion among samples in the feature space when a single date image is being used to produce the classification map. This generally results in a poorly classified map, where non-rare pasturelands are wrongly predicted as if they were crop areas, and crop areas as pasturelands. Incorporating time in scheme classification might be the solution for this issue, once each different surface pattern have its own behaviour along the time, and this is what differs the land use and land cover, although the similarity in spectral response they may present. Time series present then a very high potential in exploring temporal variations of pixels' reflectance values in a sequence of satellite imagery, allowing the usage of this information for better discrimination of targets spectrally similar.

Many researches has been conducted in order to analyse the distinction between patterns using time series, thus, exploring the temporal behaviour of the targets to assist the discrimination among them (Malaquias et al., 2017; Parente \& Ferreira, 2017; Santos et al., 2017; Souza et al., 2017; Costa et al., 2018; Costa, 2019; Bendini et al., 2019). Parente et al. (2017) and Parente (2017) tried to map Brazil's pasturelands using time series of the Landsat products for the year 2015. They used the bands of the OLI sensor to derive metric images as well as vegetation indexes and LSMM (Linear Spectral Mixture Model) fraction images so as to compose the feature space. Parente \& Ferreira (2018) attempted to assess the dynamics of the pasturelands in Brazilian territory using time series from 2000 to 2016 of the products of MODIS satellite. Likewise, Parente et al. (2019) used time series derived from Landsat 8 products, this turn composing a historical series from 1985 to 2017 , to evaluate the pasturelands and livestock dynamics along the Brazilian territory through these years. All of these works culminated in an effort triggered by several crews and institutes, which intended to yield annual land-use and land-cover maps for the Brazil entire territory using the whole Landsat historical observation archive. This project was named Mapbiomas.

However, these approaches have in common the fact that they did not consider the spatial correlation among the pixels during the classifying process (Assis et al., 2016), what may lead to classification inconsistencies such as salt-and-pepper noise, which is inherent to pixel-based classifications (Campos et al., 2013). At this aspect, geographic object-based image analysis (GEOBIA) may lend a set of tools to attend this demand, as it provides a manner to take in consideration the spatial correlation among the pixels (Hay \& Castilla, 2008; Blaschke, 2010; Blaschke at al., 2014; Körting, 2012). Once we found this gap in literature, we tackled to obtain a satisfactory distinction between pasture and croplands in Brazilian Cerrado biome, using a set of metric images derived from one-year time series of Landsat 8 products, considering attributes both spectral and geometrical, extracted from the objects of a segmented dataset.

\footnotetext{
* Corresponding author
} 


\section{MATERIAL AND METHODS}

\subsection{Data and study area}

In this work, the methodological approach was implemented in a stepwise guided by the stages depicted in Figure 1. Landsat 8 satellite imagery (Roy et al., 2014) was used as data source and six bands of the OLI sensor were elected to perform the procedures, which are the bands 2 to 7 . In order to achieve the objectives, methodology was led by a first step of images download followed by bands election.

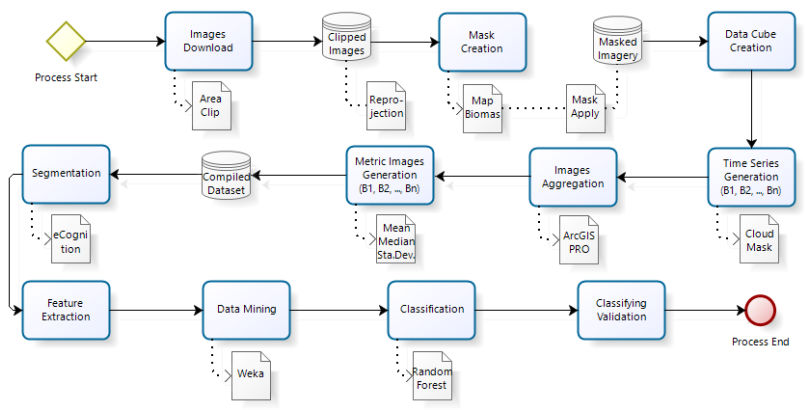

Figure 1. Methodological approach flow chart.

This work was conducted in a subset of Brazilian Cerrado biome and comprises an area of approximately $625 \mathrm{~km}^{2}$, with sides roughly of $25 \mathrm{~km}$ long. The subset is placed over Goiás state and includes portion of four municipalities: Cachoeira Alta, Caçu, Itarumã and Paranaiguara. As the Landsat archive is set to the Northern hemisphere, all data was reprojected to the Southern hemisphere, changing the datum from WGS84 to SIRGAS2000, which has a better adjustment to the South American continent, although they both use the same GSR-80 revolution ellipsoid.

Study area was intentionally located in the overlaying swath of two Landsat adjacent orbits (Luiz et al., 2015), intending to boost the time series by twofolding the number of observations, once the analysis was done considering a year, which was 2018. We chose this year to perform the analysis because it is the latest entire year of Landsat imagery by the time of this work. In addition, to get a complete year of phenological characteristics of the targets. This way, we went from 22-23 images (the amount of Landsat observations in a unique scene a year, due to its 16-days revisit time) to 45 images, increasing the time series observations. Thus, study area comprises images of both 222/73 and 223/73 scenes (Figure 2). All images were then clipped to the subset limits to enclose the data into the study area.

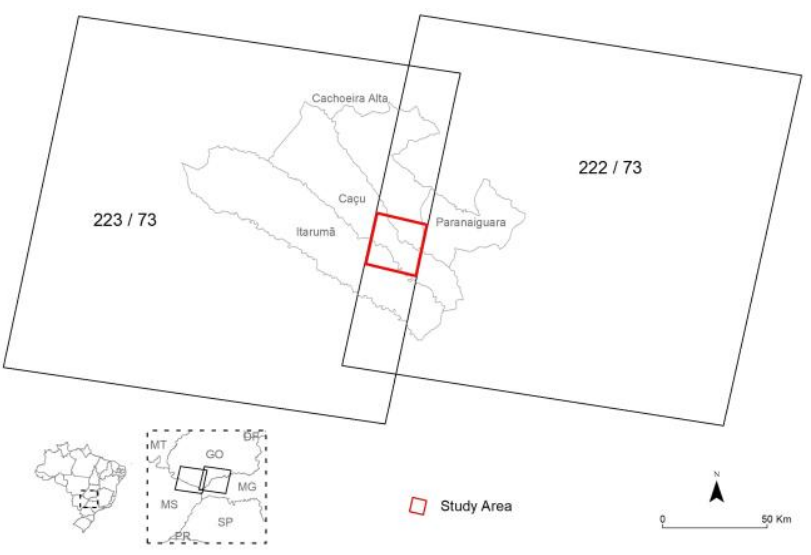

Figure 2. Overlaying Landsat swath and study area.

\subsection{Spectral similarity}

Once the study area holds other types of land cover, beyond the ones herein analysed, it was needed to take these areas off of the data. To do so, we used the Mapbiomas land cover map to mask non-pasture and non-croplands patterns in study area. Figure 3 depicts the other types of land cover that were masked using Mapbiomas classification as reference. Regarding the objective of this work, it was necessary to do because having other types of land cover in the study area could cause a non-holistic analysis between the separation concerning pasture and croplands specifically, once other classes might interfere with omission/commission errors due to their spectral response, rendering a misunderstanding of the confusion between pasture and croplands (Müller et al., 2015).

Aiming to deeply exam the confusion between the patterns above cited, we checked the spectral similarity among them by means of analysing their spectral signature besides their appearance in a true colour image. Figure 4 presents a dry season image clipping of the study area, extracted from Google Earth (GE), together with two panels, one showing an enlarging of a pasture area, and the other one, an enlarging of a cropland. Figure 5, by its turn, presents the spectral curves of both pasture and croplands patterns, yielded from several samples of each, considering the OLI sensor bands herein explored.

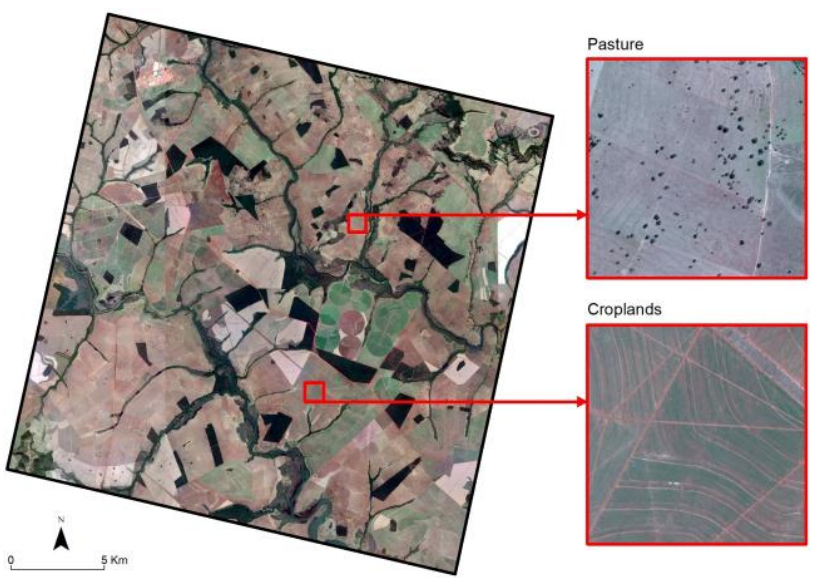

Figure 4. Dry season true colour image of the study area.

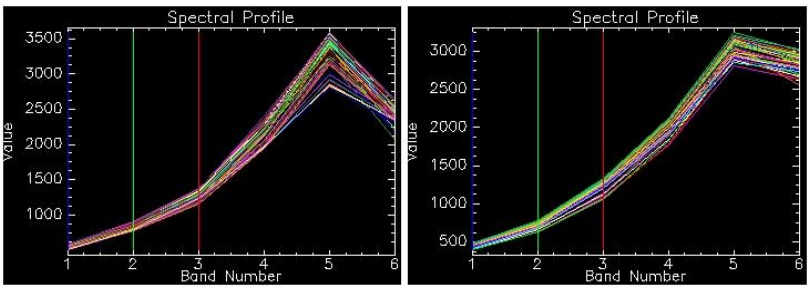

Figure 5. Spectral profiles of pasture (left) and cropland (right).

As it can be seen, both true colour image and spectral profiles show the similarity between pasture and croplands, and it is especially important for the latter, once those are the information that the classifier algorithms use to perform the classification, and where the confusion arise. Spectral curves of both patterns are practically the same, except concerning the croplands sixth band (SWIR 2), for which the reflectance values are slightly higher. It implies that during the classification process, dry pasture may be confused with fallow areas, which hold different land use and cannot be ensembled in the same class. Although this analysis have been done for the dry season, in the wet season the same occurs, however regarding the greenness of both pasture grasslands and growing croppings. 

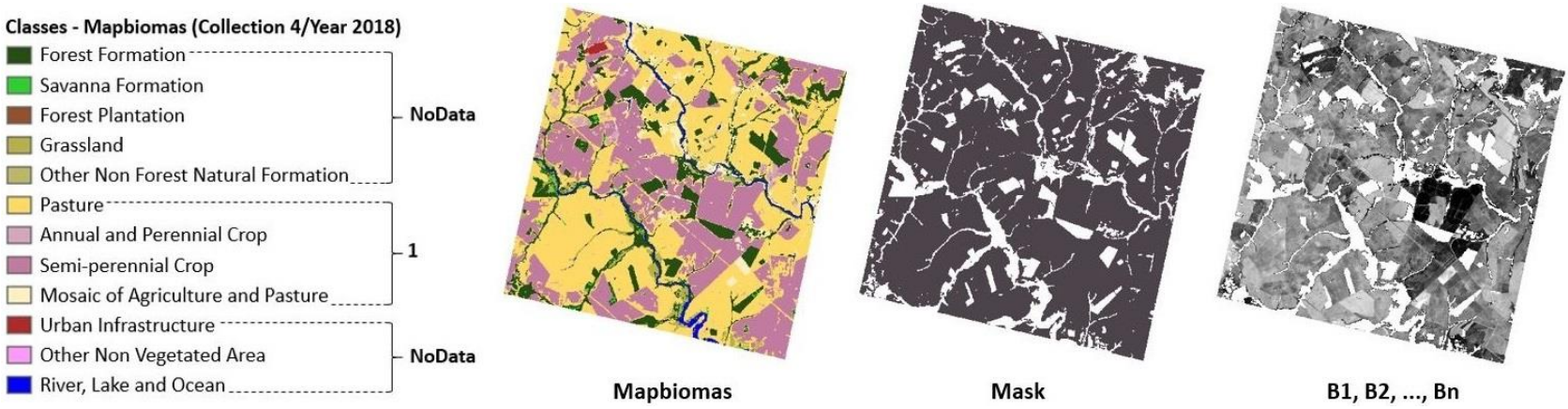

Figure 3. Land use and Land cover in the study area according to the Mapbiomas classification, and masking stages.

\subsection{Data cube, time series and cloud coverage}

Next, we created a data cube (Appel \& Pabesma, 2019) containing six dimensions, which are represented by the bands prior mentioned. Time series, hence, will have six dimensions as well. In our methodological approach, feature space is composed by the values of metric images calculated from the time series of each band. Each one of the bands along the time were aggregated into one single image (Gregory, 2003), which represents a calculated metric. Seven metrics were calculated: mean, median, maximum, minimum, range, standard deviation and sum (Körting, Câmara \& Fonseca, 2013). Then, we gathered all resulted data in a unique dataset containing 42 metric images, in which further procedures were applied.

We observed that cloud coverage is quite present in our time series. From the total of 45 images, 37 are affected by some cloud cover. In order to analyse the impact of cloud coverage in the time series, we divided the images in six groups according to the level of coverance: (i) free at all; (ii) rather free; (iii) low medium; (iv) high medium; (v) almost total; and (vi) total, as depicted in Figure 6. It is worth mentioning that this coverage index was not created based on percentage levels, but in the visual appearance. Table 1 shows the coverence classes and the amount of images embedded in each, as well as its percentile.
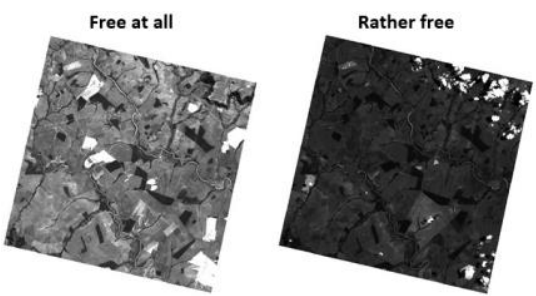

Almost total
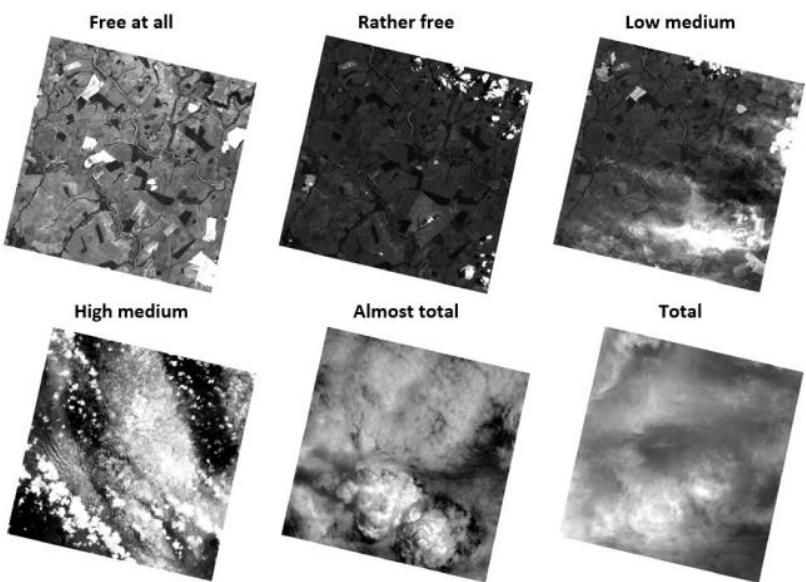

Total

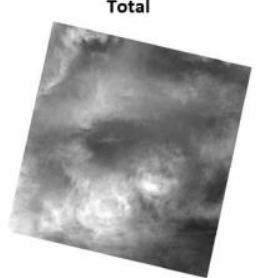

Figure 6. Cloud coverage levels.

\begin{tabular}{lcc}
\hline \multicolumn{1}{c}{ Coverance } & Observations & Percentile (\%) \\
\hline Total & 7 & 15,56 \\
Almost total & 7 & 15,56 \\
High medium & 8 & 17,78 \\
Low medium & 9 & 20,00 \\
Rather free & 6 & 13,33 \\
Free at all & 8 & 17,78 \\
\multicolumn{1}{c}{-} & $\mathbf{4 5}$ & $\mathbf{1 0 0 , 0 0}$ \\
\hline
\end{tabular}

Table 1. Cloud coverage index and its related image amount.
Intending to analyse the magnitude impact of the cloud coverage over the data, hence trying to avoid a great reduction in the time series, we tested what it would be like calculating the metrics with the clouds though, creating different datasets with each one of the groups of cloud coverance. First, we gathered only free at all images in a new dataset, then free at all and rather free, then free at all up to low medium, and so on. After all these datasets were created, we calculated the mean and created an image with this metric for each dataset. As a result, we observed that no matter the cloud coverage level, magnitude of cloud coverance over the time series is still an issue, even if considered only low coverance (rather free images).

Therefore, we reduced the amount of images composing the time series due to the quality of images, thus, decreasing the number of observations, going from the 45 initials, to eight images free at all of clouds, which were the images actually available to compose the time series. Thus, the image metrics were recalculated, now using only the eight images just mentioned, and the benchmark dataset was recreated. Despite this decrease in the time series observations, the amount of images composing the final compiled dataset remained the same, 42 , once the number of bands and metrics calculated from them kept likewise the same.

\subsection{Object-based classification and feature selection}

In our methodology, we focused in an object-oriented supervised classification, so as to consider spatial correlation among the pixels, beyond the spectral information only. Compiled dataset underwent a segmentation process driven in the eCognition (C) software. It created 7344 objects well fitted to the features on the surface. To do so, it was used the multiresolution segmentation algorithm (Baatz \& Schäpe, 2000), with scale parameter of 100 , shape 0.1 and compactness 0.5 . This step is followed by the feature extraction. Figure 7 depicts the methodological approach in a more detailed way.

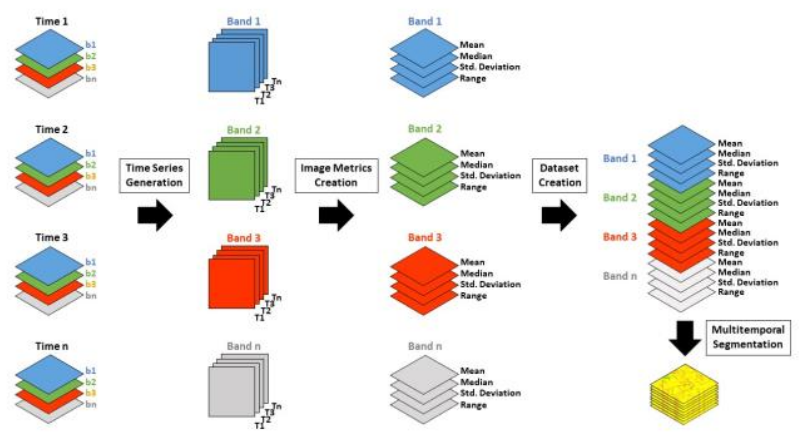

Figure 7. Detailed methodological approach flow chart. 


\begin{tabular}{|c|c|c|c|c|c|c|}
\hline \multicolumn{4}{|c|}{83 Attributes Classification } & \multicolumn{3}{|c|}{37 Attributes Classification } \\
\hline \multicolumn{2}{|c|}{ Geometrical Attributes } & \multicolumn{2}{|c|}{ Spectral Attributes } & \multicolumn{2}{|c|}{ Geometrical Attributes } & \multirow{2}{*}{$\begin{array}{l}\text { Spectral Attributes } \\
\text { Brightness }\end{array}$} \\
\hline Area & $\begin{array}{l}\text { Length/Wdth (only } \\
\text { main line) }\end{array}$ & Border Contrast & $\begin{array}{l}\text { Mean of } \\
\text { inner border }\end{array}$ & Area & $\begin{array}{l}\text { Number of edges } \\
\text { (polygon) }\end{array}$ & \\
\hline $\begin{array}{l}\text { Area (excluing } \\
\text { inner polygons) }\end{array}$ & Main direction & Brightness & $\begin{array}{l}\text { Mean of } \\
\text { outer border }\end{array}$ & $\begin{array}{l}\text { Area (excluing } \\
\text { inner polygons) }\end{array}$ & $\begin{array}{l}\text { Number of inner } \\
\text { objects (polygon) }\end{array}$ & Max. diff. \\
\hline $\begin{array}{l}\text { Area (incluing } \\
\text { inner polygons) }\end{array}$ & $\begin{array}{l}\text { Maximum } \\
\text { branch length }\end{array}$ & $\begin{array}{l}\text { Circular } \\
\text { Mean }\end{array}$ & Min. pixel value & $\begin{array}{l}\text { Area (incluing } \\
\text { inner polygons) }\end{array}$ & Number of pixels & Mean \\
\hline Asymmetry & $\begin{array}{l}\text { Number of edges } \\
\text { (polygon) }\end{array}$ & $\begin{array}{l}\text { Circular } \\
\text { StdDev }\end{array}$ & mode(Minimum & Asymmetry & Perimeter (polygon) & mode(Minimum) \\
\hline $\begin{array}{l}\text { Average branch } \\
\text { length }\end{array}$ & $\begin{array}{l}\text { Number of inner } \\
\text { objects (polygon) }\end{array}$ & $\begin{array}{l}\text { Circular } \\
\text { StdDev/Mean }\end{array}$ & $\begin{array}{l}\text { Number of } \\
\text { brighter objects }\end{array}$ & $\begin{array}{l}\text { Average length of } \\
\text { edges (polygon) }\end{array}$ & $\begin{array}{l}\text { Polygon self-inter- } \\
\text { section (polygon) }\end{array}$ & quantile(50) \\
\hline $\begin{array}{l}\text { Average length of } \\
\text { edges (polygon) }\end{array}$ & Number of pixels & $\begin{array}{l}\text { Contrast to } \\
\text { neighbor pixels }\end{array}$ & $\begin{array}{l}\text { Number of } \\
\text { darker objects }\end{array}$ & Border index & $\begin{array}{l}\text { Radius of largest } \\
\text { enclosed ellipse }\end{array}$ & Standard daviation \\
\hline $\begin{array}{l}\text { Avrg. Area represen- } \\
\text { ted by segments }\end{array}$ & Number of segments & $\begin{array}{l}\text { Edge Contrast of } \\
\text { neighbor pixels }\end{array}$ & quantile(50) & Border Length & $\begin{array}{l}\text { Radius of smallest } \\
\text { enclosed ellipse }\end{array}$ & \\
\hline Border index & Perimeter (polygon) & $\begin{array}{l}\text { HSI Trans- } \\
\text { formation Hue }\end{array}$ & Ratio & Compactness & Rectangular Fit & \\
\hline Border Length & $\begin{array}{l}\text { Polygon self- } \\
\text { intersection (polygon) }\end{array}$ & Max. diff. & Ratio to scene & $\begin{array}{l}\text { Compactness } \\
\text { (polygon) }\end{array}$ & $\begin{array}{l}\text { Rel. Border to } \\
\text { Image Border }\end{array}$ & \\
\hline Compactness & $\begin{array}{l}\text { Radius of largest } \\
\text { enclosed ellipse }\end{array}$ & Max. pixel value & $\begin{array}{l}\text { Ratio to } \\
\text { super-object }\end{array}$ & Density & Roundness & \\
\hline $\begin{array}{l}\text { Compactness } \\
\text { (polygon) }\end{array}$ & $\begin{array}{l}\text { Radius of smallest } \\
\text { enclosed ellipse }\end{array}$ & $\begin{array}{l}\text { Mean diff. to bri- } \\
\text { ghter neighbors }\end{array}$ & $\begin{array}{l}\text { Rel. border to } \\
\text { brighter objects }\end{array}$ & Eliptic Fit & Shape index & \\
\hline $\begin{array}{l}\text { Curvature/length } \\
\text { (only main line) }\end{array}$ & Rectangular Fit & $\begin{array}{l}\text { Mean diff. to } \\
\text { darker neighbors }\end{array}$ & Skewness & Length & $\begin{array}{l}\text { Stddev of length of } \\
\text { edges (polygon) }\end{array}$ & \\
\hline $\begin{array}{l}\text { Degree of skeleton } \\
\text { branching }\end{array}$ & $\begin{array}{l}\text { Rel. area to } \\
\text { super-object }\end{array}$ & $\begin{array}{l}\text { Mean Diff. to } \\
\text { neighbors (abs) }\end{array}$ & $\begin{array}{l}\text { Standard } \\
\text { daviation }\end{array}$ & $\begin{array}{l}\text { Length of longest } \\
\text { edge (polygon) }\end{array}$ & Thickness & \\
\hline Density & $\begin{array}{l}\text { Rel. Border to } \\
\text { Image Border }\end{array}$ & $\begin{array}{l}\text { Mean Diff. } \\
\text { to neighbors }\end{array}$ & $\begin{array}{l}\text { StdDev diff. to } \\
\text { super-object }\end{array}$ & Length/Thickness & Volume & \\
\hline $\begin{array}{l}\text { Distance to super- } \\
\text { object center }\end{array}$ & $\begin{array}{l}\text { Rel. inner border } \\
\text { to super-object }\end{array}$ & $\begin{array}{l}\text { Mean diff. } \\
\text { to scene }\end{array}$ & $\begin{array}{l}\text { StdDev Ratio to } \\
\text { super-object }\end{array}$ & Length/Width & Width & \\
\hline $\begin{array}{l}\text { Eliptic distance to } \\
\text { super-object center }\end{array}$ & $\begin{array}{l}\text { Rel. rad. position } \\
\text { to super-object }\end{array}$ & $\begin{array}{l}\text { Mean diff. to } \\
\text { super-object }\end{array}$ & $\begin{array}{l}\text { StdDev. to } \\
\text { neighbor pixels }\end{array}$ & Main direction & & \\
\hline Eliptic Fit & Roundness & Mean & & & & \\
\hline $\begin{array}{l}\text { Is center of } \\
\text { super-object }\end{array}$ & Shape index & & & & & \\
\hline Is end of super-object & $\begin{array}{l}\text { Stddev Curvature } \\
\text { (only main line) }\end{array}$ & & & & & \\
\hline Length & $\begin{array}{l}\text { Stddev of area repre- } \\
\text { sented by segments }\end{array}$ & & & & & \\
\hline $\begin{array}{l}\text { Length of longest } \\
\text { edge (polygon) }\end{array}$ & $\begin{array}{l}\text { Stddev of length of } \\
\text { edges (polygon) }\end{array}$ & & & & & \\
\hline $\begin{array}{l}\text { Length of main line } \\
\text { (no cycles) }\end{array}$ & Thickness & & & & & \\
\hline $\begin{array}{l}\text { Length of main line } \\
\text { (regarding cycles) }\end{array}$ & Volume & & & & & \\
\hline Length/Thickness & Width & & & & & \\
\hline Length/Width & Width (only main line) & & & & & \\
\hline
\end{tabular}

Table 2. Both geometrical and spectral attributes used in the classifications.

With the aim of enhance the classification results, feature extraction was conducted considering both spectral and geometric contexts. Thus, it was selected spectral attributes, such as mean and standard deviation of the pixel values in each polygon (object), as well as geometrical attributes, such as area and border length of each polygon likewise. After the feature extraction, these attributes were involved in a data mining process (Fayyad, Piatetsky-Shapiro \& Smyth, 1996) in the Weka software. In the same platform, the Random Forest algorithm (Breiman, 2001) was elected to perform the classification due to its ability to deal with large data not overfitting. The model was trained using 100 trees to compose the forest depth.

\subsection{Methodology assessment and classifying validation.}

We tackled the analysis by means of quantity of attributes involved in the classification. In order to assess the contribution of the attributes quantity in the algorithm performance, we did the classification twice, on the one hand considering 83 attributes, among spectral and geometrical, and on the other hand, we decreased the quantity, using 37 attributes, among spectral and geometrical as well. List of the attributes, both spectral and geometrical, utilized in the classifications can be consulted in the Table 2.

Training phase was done by means of electing specific polygons for each class from the segmentation archive considering GE images as reference (Olofsson, et al., 2014). These images are dated from $25^{\text {th }}$ July 2018, therefore, according to the date of our methodological approach. Thus, we used GE images to classify manually the selected polygons, which would be then utilized as samples to train the automated classifier algorithm.

Likewise, accuracy assessment was made considering GE images. We plotted 200 points, randomly spread along the study area, and classified each one of them according to their actual land cover as it was seen in GE images. This way, GE images were considered as our ground truth. After all accuracy points were classified, we performed the accuracy assessment by means of cross validation. It is also worth mentioning that these validation procedures were applied to both classifications using the same set of points (Colditz, 2015). 

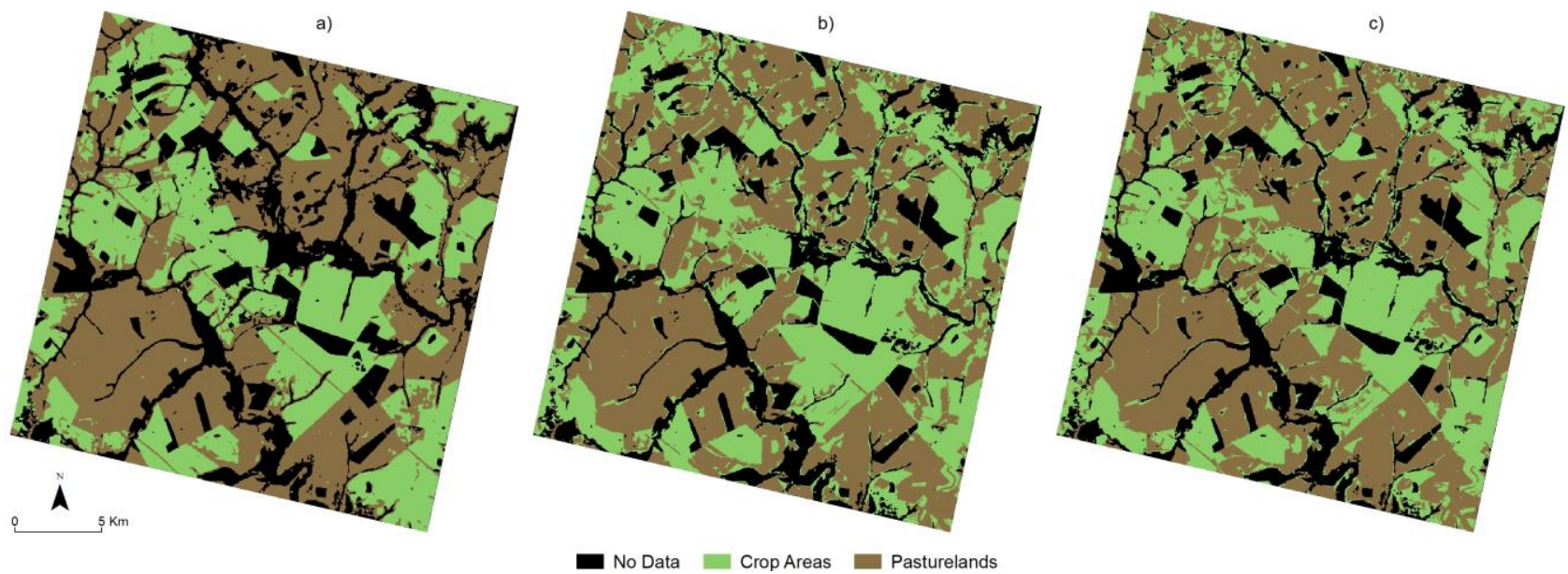

Figure 8. Comparison between: a) Mapbiomas classification; b) 83 attributes classification; and c) 37 attributes classification.

\section{RESULTS AND DISCUTION}

The results evaluation was conducted by means of both analysis of the confusion matrices values and comparison of the classification results with the Mapbiomas classification map, which is being considered in this work as reference of accuracy. Global accuracies and kappa indexes of both classifications were very similar, although they were slightly higher for the 37 attributes classification. These values for the 83 attributes classification were $80 \%$ and 0.6 , respectively, whereas for the 37 attributes classification were $81 \%$ and 0.61 . In the same way, user/producer accuracies and commission/omission errors of the classes were close to, ranging no more than three percentile points.

For the sake of the proximity concerning the accuracy values, this may not be the best method to assess which one of the classifications had the best performance. In fact, considering the comparison between the results depicted in Figure 8, they appear to be alike, although there has been uncertainties between them. Despite their likeness, 83 attributes classification visually seems to be closer to the Mapbiomas classification, rather than the 37 attributes classification. Although there had been misclassification, polygons of the first approach matches to the reference better than the latter ones.

This approaching between the results reveals that increasing the number of attributes feeding the classifier do not yield better results. It seems like reaching a specific number of attributes, classification achieves a level of performance, that increasing them do not corroborate for bettering the results. However, regardless the accuracy in terms of values, we saw a tendency of an increasing in the rightness of the classification with the increase of the number of attributes. Thus, there may be in actual gains in the classification results increasing the quantity of attributes, and the coincidence in the accuracy values may be accounted to statistical issues regarding the sampling strategy.

\section{CONCLUSIONS AND FINAL REMARKS}

With this work, we showed the potential of the time series, coupled with the use of geometrical attributes, in separating targets spectrally similar during the classification process. It is also important to highlight the contribution that working on the overlaying swath of Landsat orbits had in the increasing of the number of observations. With this strategy, we could retain in the time series a quantity of images that were still favourable to the classifier algorithm to identify the temporal behaviour of the targets and thus differentiate between them. If instead of it were used images of only one scene, maybe we would not have consistent images to compose the time series due to the reduction owed to the cloud coverage.

Of course, the reduction that time series underwent for the sake of cloud coverage contributed for the underrated predictions that both classifications went through, given the misclassification we observed in both cases. In spite of it, we still observed a consistency in the results, regarding the correspondence between them and the classification reference. This points to the potential contribution of this methodology and implies that with a wider and denser time series we might reduce the impact of cloud coverage, once we might have more images free of clouds. Thus, we might yield classifications much more faithful and loyal to the ground truth, as a higher quantity of temporal characteristics of the targets would be preserved.

Finally, it is worth to say that working on the overlaying swaths, intending to obtain more robust time series, may restrict the area of analysis, once swaths overlay in a relatively narrow path, around $20 \mathrm{~km}$ wide close to Equator, increasing toward the poles. To solve this issue, strategies of integrating data from different sensors using harmonizing techniques, therefore, magnifying the number of observations, allow the execution of the analysis not only in the overlaying swaths, but in any area where these techniques are implemented.

\section{ACKNOWLEDGEMENTS}

This study was financed in part by the Coordenação de Aperfeiçoamento de Pessoal de Nível Superior - Brasil (CAPES) - Finance Code 001.

\section{REFERENCES}

APPEL, Marius; PEBESMA, Edzer. On-demand processing of data cubes from satellite image collections with the gdalcubes library. Data, v. 4, n. 3, 2019.

ASSIS, Luiz Fernando; RIBEIRO, Gilberto; FERREIRA, Karine Reis; et al. Big data streaming for remote sensing time series analytics using MapReduce. Proceedings of the Brazilian Symposium on GeoInformatics, v. 2016-November, n. November, p. 228-239, 2016. 
BAATZ, Martin; SCHÄPE, Arno. Multiresolution segmentation: an optimization approach for high quality multi-scale image segmentation Journal of Photogrammetry and Remote Sensing, v58, n. 3-4, p. 12-13, 2000

BENDINI, Hugo do Nascimento; FONSECA, Leila Maria Garcia; SCHWIEDER, Marcel; et al. Detailed agricultural land classification in the Brazilian cerrado based on phenological information from dense satellite image time series. International Journal of Applied Earth Observation and Geoinformation, v. 82, n. May, p. 101872, 2019. Disponível em: 〈https://doi.org/10.1016/j.jag.2019.05.005〉.

BLASCHKE, T. Object based image analysis for remote sensing. ISPRS Journal of Photogrammetry and Remote Sensing, v. 65, n. 1, p. 2-16, 2010. Disponível em: <http://dx.doi.org/10.1016/j.isprsjprs.2009.06.004>.

BLASCHKE, Thomas; HAY, Geoffrey J.; KELLY, Maggi; et al Geographic Object-Based Image Analysis - Towards a new paradigm. ISPRS Journal of Photogrammetry and Remote Sensing, v. 87, p. 180191, 2014. Disponível em: <http://dx.doi.org/10.1016/j.isprsjprs.2013.09.014>.

BREIMAN, Leo. Random forests. Machine learning, v. 45, n. 1, p. 5 $32,2001$.

CAMPOS, Alessandro Ribeiro; FONSECA, Diego Ferreira; SAMPAIO, Daniel Martins; et al. Classificação orientada a objeto para mapeamento do uso e cobertura do solo do município de Rio Acima - MG: por crescimento de regiões e por extração de objetos. Anais do XVI Simpósio Brasileiro de Sensoriamento Remoto, p. 6917-6922, 2013.

COLDITZ, René Roland. An evaluation of different training sample allocation schemes for discrete and continuous land cover classification using decision tree-based algorithms. Remote Sensing, v. 7, n. 8, p. 9655-9681, 2015.

COSTA, Wanderson Santos; FONSECA, Leila Maria Garcia KORTING, Thales Sehn; et al. Spatiooral segmentation applied to optical remote sensing image time series. IEEE Geoscience and Remote Sensing Letters, v. 15, n. 8, p. 1299-1303, 2018.

COSTA, Wanderson. Segmentação de imagens de sensoriamento remoto baseada em séries temporais e DTW. Tese (Doutorado) do Curso de Pós-Graduação em Computação Aplicada - INPE, p. 97, 2019.

FAYYAD, Usama; PIATETSKY-SHAPIRO, Gregory; SMYTH, Padhraic. From data mining to Knowledge Discovery in Databasis. AI Magazine, v. 17, n. 3, p. 37, 1996.

GREGORY, J. The CF metadata standard. CLIVAR Exchanges, v. 8, $\mathrm{n}$. 4, p. 4, 2003. Disponível em <http://cfconventions.org/\%5Cnhttps://en.wikipedia.org/wiki/Climate_ and_Forecast_Metadata_Conventions>.

HAY, Geoffrey J; CASTILLA, Guillermo. Geographic Object-Based Image Analysis (GEOBIA): A new name for a new discipline. In: BLASCHKE, Thomas; LANG, Stefan; HAY, Geoffrey J. Preface. Object-Based Image Analysis: Spatial Concepts for Knowledge-Driven Remote Sensing Applications, n. February 2017, p. V-VIII, 2008. Disponível em: 〈https://doi.org/10.1007/978-3-540-77058-9>.

KORTING, Thales Sehn. GeoDMA : a toolbox integrating data mining with object-based and multi-temporal analysis of satellite. Tese (Doutorado) do Curso de Pós-Graduação em Sensoriamento Remoto INPE, p. 123, 2012.

KÖRTING, TS; CÂMARA, G; FONSECA, LMG; et al. Land cover detection using temporal features based on polar representation. $\mathrm{n}$. August, p. 0-5, 2013.
LUIZ, Alfredo José Barreto; SANCHES, Ieda Del'Arco; TRABAQUINI, Kleber; et al. Dinâmica agrícola em área de sobreposição de órbitas adjacentes dos satélites Landsat. Anais XVII Simpósio Brasileiro de Sensoriamento Remoto - SBSR, João PessoaPB, Brasil, 25 a 29 de abril de 2015, INPE, n. 1, p. 6381-6388, 2015.

MALAQUIAS, Fernanda Stefani Souza; TEIXEIRA, Lana Mara Silva; SANTIAGO, Rhuan Bruno Silva; et al. Pastagem.org: dados e informações para uma compreensão ambiental, econômica e social sobre a última fronteira agrícola do Brasil. XVIII Simpósio Brasileiro de Sensoriamento Remoto -SBSR, p. 1392-1399, 2017. Disponível em: <http://marte2.sid.inpe.br/rep/sid.inpe.br/marte2/2017/10.23.19.36.10〉

MÜLLER, Hannes; RUFIN, Philippe; GRIFFITHS, Patrick; et al Mining dense Landsat time series for separating cropland and pasture in a heterogeneous Brazilian savanna landscape. Remote Sensing of Environment, v. 156, p. 490-499, 2015.

OLOFSSON, Pontus; FOODY, Giles M.; HEROLD, Martin; et al. Good practices for estimating area and assessing accuracy of land change. Remote Sensing of Environment, v. 148, p. 42-57, 2014. Disponível em: 〈http://dx.doi.org/10.1016/j.rse.2014.02.015〉.

PARENTE, Leandro Leal. Mapeamento das pastagens brasileiras a partir da classificação automática de métricas espectro-temporais derivadas de dados Landsat 8. Tese (Doutorado) do Curso de PósGraduação em Ciências Ambientais - UFG, p. 96, 2017.

PARENTE, Leandro Leal; FERREIRA, Laerte Guimarães. Desafios e oportunidades para o monitoramento da cobertura terrestre brasileira utilizando séries temporais Landsat. Anais do XVIII Simpósio Brasileiro de Sensoriamento Remoto -SBSR, p. 2146-2152, 2017.

PARENTE, Leandro; FERREIRA, Laerte; FARIA, Adriano; et al. Monitoring the brazilian pasturelands: A new mapping approach based on the landsat 8 spectral and temporal domains. International Journal of Applied Earth Observation and Geoinformation, v. 62, n. January, p. 135-143, 2017. Disponível em: <http://dx.doi.org/10.1016/j.jag.2017.06.003>.

PARENTE, Leandro; FERREIRA, Laerte. Assessing the spatial and occupation dynamics of the Brazilian pasturelands based on the automated classification of MODIS images from 2000 to 2016. Remote Sensing, v. 10, n. 4, 2018.

PARENTE, Leandro; MESQUITA, Vinícius; MIZIARA, Fausto; et al Assessing the pasturelands and livestock dynamics in Brazil, from 1985 to 2017: A novel approach based on high spatial resolution imagery and Google Earth Engine cloud computing. Remote Sensing of Environment, v. 232, n. October 2018, p. 111301, 2019. Disponível em: 〈https://doi.org/10.1016/j.rse.2019.111301>.

PROJETO MAPBIOMAS - Coleção 4 da Série Anual de Mapas de Cobertura e Uso de Solo do Brasil, acessado em 04 de novembro de 2019 através do link: 〈https://mapbiomas.org/>.

ROY, D. P.; WULDER, M. A.; LOVELAND, T. R.; et al. Landsat-8: Science and product vision for terrestrial global change research Remote Sensing of Environment, v. 145, p. 154-172, 2014. Disponível em: <http://dx.doi.org/10.1016/j.rse.2014.02.001>.

SANTOS, Claudinei Oliveira; ARANTES, Arielle Elias; ANDRADE, Ana Carolina do Couto; et al. Análise da produtividade e degradação das pastagens do Brasil por meio de séries temporais MODIS GPP. p. 5327-5333, 2017.

SOUZA, Guilherme Ferreira Arantes; ARANTES, Arielle Elias; PARENTE, Leandro Leal; et al. Padrões e tendências das pastagens do Brasil: uma análise a partir de imagens índice de vegetação MODIS e algoritmos de detecção de mudanças. Anais do XVIII Simpósio Brasileiro de Sensoriamento Remoto -SBSR, p. 4977-4984, 2017. 